\title{
Estrogen Alters Spine Number and Morphology in Prefrontal Cortex of Aged Female Rhesus Monkeys
}

\author{
Jiandong Hao, ${ }^{1}$ Peter R. Rapp, ${ }^{1,2}$ Abba E. Leffler, ${ }^{1}$ Shoshana R. Leffler, ${ }^{1}$ William G. M. Janssen, ${ }^{1}$ Wendy Lou, ${ }^{6}$ \\ Heather McKay, ${ }^{5}$ Jeffrey A. Roberts, ${ }^{7}$ Susan L. Wearne, ${ }^{1,3,4}$ Patrick R. Hof, ${ }^{1,2,4}$ and John H. Morrison ${ }^{1,2,4}$ \\ ${ }^{1}$ Fishberg Department of Neuroscience and Kastor Neurobiology of Aging Laboratories, ${ }^{2}$ Department of Geriatrics and Adult Development, ${ }^{3} \mathrm{Center}$ for \\ Biomathematical Sciences, ${ }^{4}$ Computational Neurobiology and Imaging Center, Mount Sinai School of Medicine, New York, New York 10029 , ${ }^{5}$ California \\ National Primate Research Center, University of California, Davis, California 95616, ${ }^{\circ}$ Department of Public Health Sciences, University of Toronto, Toronto, \\ Ontario, Canada M5T 3M7, and 7Valley Biosystems, West Sacramento, California 95605
}

Long-term cyclic treatment with $17 \beta$-estradiol reverses age-related impairment in ovariectomized rhesus monkeys on a test of cognitive function mediated by the prefrontal cortex (PFC). Here, we examined potential neurobiological substrates of this effect using intracellular loading and morphometric analyses to test the possibility that the cognitive benefits of hormone treatment are associated with structural plasticity in layer III pyramidal cells in PFC area $46.17 \beta$-Estradiol did not affect several parameters such as total dendritic length and branching. In contrast, $17 \beta$-estradiol administration increased apical and basal dendritic spine density, and induced a shift toward smaller spines, a response linked to increased spine motility, NMDA receptor-mediated activity, and learning. These results document that, although the aged primate PFC is vulnerable in the absence of factors such as circulating estrogens, it remains responsive to long-term cyclic $17 \beta$-estradiol treatment, and that increased dendritic spine density and altered spine morphology may contribute to the cognitive benefits of such treatment.

Key words: plasticity; neocortex; estradiol; hormone; cognition; pyramidal cell

\section{Introduction}

Although data on cognition, menopause, and hormone treatments for women remain controversial (Turgeon et al., 2004), the preclinical evidence is unambiguous in demonstrating neuroprotection (Nilsen and Brinton, 2002) and synaptic effects of estrogens on circuits that mediate memory and cognition (McEwen, 2001). For example, there is evidence that $17 \beta$-estradiol increases the density of dendritic spines and axospinous synapses on CA1 pyramidal cells of young female rats (Gould et al., 1990; Woolley and McEwen, 1992), and these effects are NMDA receptordependent (Woolley and McEwen, 1994). 17 $\beta$-Estradiol increases NMDA receptor levels (Gazzaley et al., 1996) and facilitates NMDA receptor-mediated responses in CA1 pyramidal neurons (Woolley et al., 1997). Effects of estrogens on GABAergic synapses (Rudick and Woolley, 2001) and cholinergic mediation of hippocampal function in young female rats have been described as well (Gibbs, 2002; Rudick et al., 2003). The data from nonhuman primates are largely consistent with rodent findings. $17 \beta$-Estradiol increases spine number in CA1 of ovariectomized

Received Aug. 15, 2005; revised Jan. 20, 2006; accepted Jan. 21, 2006.

This work was supported by National Institutes of Health Grants AG16765, AG06647, AG10606, MH58911, MH60734, and RR16754. We thank Ginelle Andrews, Susan Fink, Murat Yildirim, Chet Sherwood, Anne Canfield, Mary Roberts, Sania Fong, Deborait Kent, Harry Arwell, and Sona Santos for technical assistance; Douglas Ehlenbergen and Alfredo Rodriguez for software development; and Anne Rocher, Jason Radley, Yong Tang, Christina Weaver, and Doron Kabaso for critical discussion.

Correspondence should be addressed to Dr. John H. Morrison, Department of Neuroscience, Box 1065, Mount Sinai School of Medicine, New York, NY 10029. E-mail: John.Morrison@mssm.edu.

DOI:10.1523/JNEUROSCI.3440-05.2006

Copyright $\odot 2006$ Society for Neuroscience $\quad$ 0270-6474/06/262571-08\$15.00/0 young African green monkeys (Leranth et al., 2002), and in young and aged female rhesus monkeys (Hao et al., 2003). Studies of young rhesus monkeys have also revealed estrogen effects on dorsolateral prefrontal cortex (PFC), including an increase in spine number (Tang et al., 2004a) in layer I, as well as enhancement of cholinergic and monoaminergic inputs to PFC (Kritzer and Kohama, 1999; Tinkler et al., 2004).

Whereas preclinical findings are consistent with the view that estrogen therapy may promote healthy cognitive aging (Zandi et al., 2002), the Women's Health Initiative (WHI) studies, which used a standard form of combined hormone treatment [conjugated equine estrogens (CEEs) and medroxyprogesterone acetate (MPA); PremPro], not only failed to slow the rate of cognitive decline in healthy postmenopausal women but significantly increased the risk for dementia and stroke (S. R. Rapp et al., 2003; Shumaker et al., 2003, 2004). The frequently contradictory data from clinical studies on the cognitive effects of hormone treatment in women have been attributed to several factors (Turgeon et al., 2004). A resolution between clinical and basic research may hinge on several issues regarding the schedule and formulation of therapy, and age at the time treatment is initiated (Simpkins and Singh, 2004). In fact, rodent studies highlight the importance of age, in that the aged female rat is less responsive to $17 \beta$-estradiol therapy with respect to CA1 synapse number (Adams et al., 2001a) and cognitive enhancement (Savonenko and Markowska, 2003), and there appears to be a "window of opportunity" after which intervention is less effective (Gibbs, 2000; Adams et al., 2001b).

Given this background, we have initiated a multidisciplinary 
analysis of $17 \beta$-estradiol treatment in aged rhesus monkeys that employs cyclical delivery of $17 \beta$-estradiol to monkeys that were ovariectomized relatively early during the course of aging (mean age of 22 years), before the onset of pronounced ovarian deficiency and cognitive impairment that might prove refractory to rescue (P. R. Rapp et al., 2003; Shideler et al., 2003). Our previously published behavioral analyses of these animals (P. R. Rapp et al., 2003) showed that this cyclical regimen of estradiol treatment reversed the most well established signature of cognitive aging in ovariectomized monkeys, the delayed response (DR) task, a behavioral assessment that critically requires the dorsolateral PFC (P. R. Rapp et al., 2003). With behavioral results directly implicating this region, we hypothesized that layer III pyramidal neurons within the dorsolateral PFC might be affected by $17 \beta$ estradiol, and such effects would impact corticocortical integration required for cognitive processes mediated by this region (Goldman-Rakic, 1996, 2002). The data presented below support this hypothesis and reveal a profound effect on pyramidal cell spines within area 46 of PFC in the same aged monkeys that displayed $17 \beta$-estradiol-induced enhancement of PFC function.

\section{Materials and Methods}

Animals and hormonal screening. Fourteen aged female rhesus monkeys (Macaca mulatta; age range, 22 years \pm 7 months), were used in this study, all of whom were previously behaviorally characterized (P. R. Rapp et al., 2003). Female rhesus monkeys can live into their early thirties, and at the age of these used for this study, they are typically just before perimenopause or early perimenopause (Gilardi et al., 1997). The monkeys were not used in any invasive or pharmacological analyses before this study and were screened for suitability for the behavioral arm of this program (P. R. Rapp et al., 2003). They were singly housed in colonies of $\sim 40$ individuals (water and monkey chow were provided in excess of nutritional needs) at the California National Primate Research Center, University of California, Davis. All experiments were conducted in compliance with the National Institutes of Health Guidelines for the Care and Use of Experimental Animals and approved by the Institutional Animal Care and Use Committee at the University of California, Davis. Candidate monkeys, classified as premenopausal and perimenopausal by their reproductive history, were selected for behavioral assessment and morphological analyses.

Ovariectomy and $17 \beta$-estradiol replacement. All animals received bilateral ovariectomies (OVXs) and were randomly assigned to age-matched OVX plus vehicle $(\mathrm{OVX}+\mathrm{Veh})$ and OVX plus estrogen $(\mathrm{OVX}+\mathrm{E})$ treatment groups. After an average post-OVX interval of $30 \pm 1.7$ weeks (mean \pm SEM), eight randomly assigned monkeys received estradiol cypionate $(100 \mu \mathrm{g} / \mathrm{ml}$ of sterile peanut oil, i.m.; Pharmacia, Peapack, NJ) in a single injection every 3 weeks. Such a formulation injected intramuscularly guarantees that the dominant active estrogen that the treated animals are exposed to is the physiologically relevant $17 \beta$-estradiol. OVX + Veh age-matched monkeys were provided an equivalent volume of vehicle injection according to the same schedule. Treatment extended over 2-3 years of behavioral testing. Estradiol cypionate and vehicle injections were coded and administered in a blinded manner until all experiments were completed, with the blind codes retained through all microscopic analyses. Serum $17 \beta$-estradiol values were measured $1 \mathrm{~d}$ before treatment and $9 \mathrm{~h}, 2 \mathrm{~d}$, and $3 \mathrm{~d}$ after treatment, and urine levels were measured at multiple time points. As detailed previously for the same animals as those examined here (P. R. Rapp et al., 2003; Shideler et al., 2003), OVX reduced serum and urinary $17 \beta$-estradiol to near zero. Estradiol cypionate injection provided every $21 \mathrm{~d}$ in treated monkeys (group OVX + E) produced a rapid rise in circulating $17 \beta$-estradiol compared with vehicle-treated animals (group OVX + Veh), which peaked within $24 \mathrm{~h}$ at levels comparable with preovulatory values in intact females, followed by decline to baseline over the next several days. The bioefficacy of hormone treatment was also confirmed by the observation that all OVX +E monkeys exhibited instances of breakthrough bleeding after treatment, whereas similar effects were not observed in vehicle- treated subjects. Behavioral testing and endocrine treatments were continued right up to the times of perfusion. As published previously for these same rhesus monkeys (P. R. Rapp et al., 2003), the cyclical $17 \beta$ estradiol regimen described above substantially reversed the age-related impairment on a DR test of spatial working memory displayed by the OVX + Veh group. In fact, the OVX +E group performed at a level on DR that was nearly equivalent to that of young intact rhesus monkeys (P. R. Rapp et al., 2003).

Perfusion and tissue processing. Animals were perfused in groups of 2 or 3 as they completed their behavioral assessment. All animals were deeply anesthetized $24 \mathrm{~h}$ after the last $17 \beta$-estradiol or vehicle treatment with ketamine hydrochloride $(25 \mathrm{mg} / \mathrm{kg})$ and pentobarbital sodium $(20-35$ $\mathrm{mg} / \mathrm{kg}$, i.v.), intubated, and mechanically ventilated. The chest was opened to expose the heart and $1.5 \mathrm{ml}$ of $0.5 \%$ sodium nitrate was injected into the left ventricle. The descending aorta was clamped and they were perfused transcardially with cold $1 \%$ paraformaldehyde in PBS for 1 min, followed by cold $4 \%$ paraformaldehyde in PBS for $12 \mathrm{~min}$. After perfusion, the brain was removed from the skull and dissected, taking care to include the entire region surrounding the principal sulcus (Brodmann's area 46) in the frontal block. The frontal block was postfixed for $6 \mathrm{~h}$ in $4 \%$ paraformaldehyde in PBS with $0.125 \%$ glutaraldehyde and then cut serially on a vibratome. A series of $400 \mu \mathrm{m}$ thick sections every $2.6 \mathrm{~mm}$ throughout area 46 were collected for intracellular injection of Lucifer yellow (LY; Molecular Probes, Eugene, OR). Because the precise position of the first slab is random, this results in a systematic random series of $8-12$ sections throughout area 46 available for cell loading. Multiple sections are used to obtain the total number of cells, such that the sampled neurons represent a random selection throughout area 46.

Intracellular injection. The approach used here was based on a modification of previous studies (Duan et al., 2003). Sections were stained with 4,6-diamidino-2-phenylindole (DAPI, a fluorescent nucleic acid stain; Sigma, St. Louis, MO) and mounted on nitrocellulose filter paper (Whatman, Maidstone, UK) immersed in $0.1 \mathrm{~m}$ PBS. Pyramidal cells from layer III of area 46 were identified under epifluorescence using a UV filter, impaled with sharp micropipettes, and loaded with 5\% LY in distilled $\mathrm{H}_{2} \mathrm{O}$ under a direct current of 3-8 nA for 5-10 min, or until the dye filled distal processes and no additional loading was observed. Generally, four to six neurons were injected per slice and injections were far enough apart to avoid overlapping of dendritic arbors, although only a subset of these were included for analysis. Sections containing loaded cells were washed, mounted, and covered with PermaFluor mounting medium (Thermo Electron, Pittsburgh, PA). To be included for threedimensional (3D) reconstruction and additional analysis, filled neurons had to satisfy three criteria: (1) be located within layer III and within the boundary of area 46 (accurate determination of cortical layers as performed on the fixed slice after counterstaining selected sections with DAPI), (2) the dendritic tree had to be filled completely, as evidenced by well defined endings, and (3) a sufficient distance between loaded cells was required to allow for unambiguous determination of the exact origin of every dendritic segment. These neurons that satisfied the criteria and were fully reconstructed thus represented a subset of the total number injected, and were distributed widely throughout area 46.

Quantitative analyses of dendritic arbors. Two animals that were behaviorally characterized (one from the OVX + Veh group and one from the $\mathrm{OVX}+\mathrm{E}$ group) were omitted from the morphological analysis because of poor tissue preservation, resulting in $n=7$ in each group. The OVX + Veh animal omitted was the same animal that failed to learn the DR task (P. R. Rapp et al., 2003). Pyramidal cell dendritic arbors (see Fig. $1 a, b$; total of 168 neurons) were reconstructed in 3D using a computerassisted morphometry system consisting of a Zeiss (Thornwood, NY) Axioplan 2 photomicroscope equipped with an Applied Scientific Instrumentation (Eugene, OR) MS-2000 XYZ computer-controlled motorized stage, a DAGE-MTI DC-330 video camera, a Gateway computer, and the NeuroLucida and NeuroExplorer morphometry software (MicroBrightField, Williston, VT). Neurons were visualized, and the dendritic tree was reconstructed using a Zeiss Apochromat $40 \times$ objective with a numerical aperture (NA) of 1.4. In this manner, the spatial coordinates of each dendritic segment were accurately recorded to enable later $3 \mathrm{D}$ rendering. Seven to 17 pyramidal cells in area 46 were reconstructed from each 

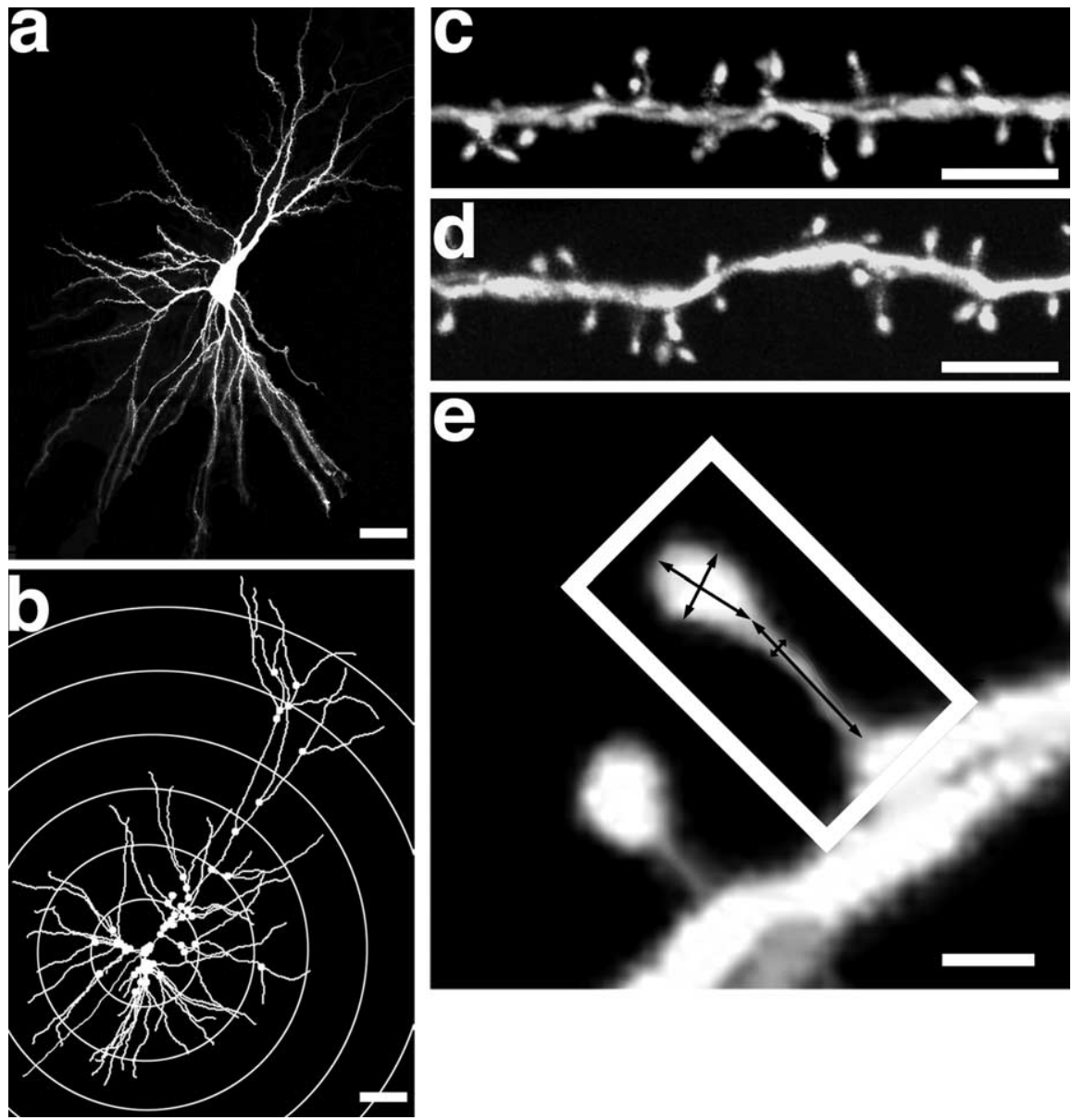

Figure 1. Representative LY-loaded, 3D reconstruction and analysis of a layer III pyramidal cell in area 46. $\boldsymbol{a}$, Example of LY-loaded layer III pyramidal cell in area 46. The NeuroLucida dataset is exported to NeuroExplorer to generate a 3D rendering of the traced neuron $(\boldsymbol{b})$. Examples of deconvolved confocal stacks from apical $(\boldsymbol{c})$ and basal $(\boldsymbol{d})$ segments are shown. The spine density was calculated for each dendritic segment that intersected with a concentric circle, as shown in $\boldsymbol{b}$. The sampled dendrites were then categorized as primary, secondary, tertiary, etc., branches to arrive at a spine density for each branch order. Single spines $(\boldsymbol{e})$ were analyzed for $H_{d \prime} H_{l,} N_{l,}$ and $N_{d}$ Scale bars: $\boldsymbol{a}, \boldsymbol{b}, 50 \mu \mathrm{m} ; \boldsymbol{c}, \boldsymbol{d}, 5 \mu \mathrm{m} ; \boldsymbol{e}, 0.5 \mu \mathrm{m}$.

monkey. NeuroLucida datasets were then exported to NeuroExplorer to generate $3 \mathrm{D}$ renderings of the traced neurons. Analyses of dendritic arbor and Sholl analyses were performed for each neuron with NeuroExplorer. Results were expressed in terms of total dendritic length, total branch number, and number of intersections and dendritic length per radial distance from the soma, in $30 \mu \mathrm{m}$ increments.

Quantitativeanalysesofspinedensityandspinemorphology. NeuroLucida/ NeuroExplorer-generated complete dendritic reconstructions were printed to allow identification of segments for spine analysis. We developed an approach that avoided sampling bias of the segments to be used for spine analysis after imaging on a confocal laser scanning microscope (CLSM; 410; Zeiss). A scaled transparency with a series of concentric circles $60 \mu \mathrm{m}$ apart was placed over each NeuroLucida reconstruction (see Fig. $1 b$ ). The points of intersection were noted as the segments to be visualized on the CLSM at high magnification. Each designated segment (25-50 $\mu \mathrm{m}$ in length) was located in the microscope field, and confocal stacks of 100-300 digital images separated by a z-step of $0.1 \mu \mathrm{m}$ were captured using a Plan-Apochromat $100 \times /$ 1.4 NA Zeiss oil-immersion objective on the CLSM. LY was excited by an $\mathrm{Ar} / \mathrm{Kr}$ laser at $488 \mathrm{~nm}$ (attenuation set at 10). All confocal stacks included at least $1 \mu \mathrm{m}$ above and below the identified dendritic segment. Settings for pinhole size, aperture, gain, and offset were optimized initially and then held constant throughout the study to ensure that all images were digitized under the same illumination conditions at a resolution of $256 \times 256$ pixels. An average of 12 high-resolution z-stacks were captured per neuron (a total of 115 neurons were used for spine analysis: 55 from OVX+Veh and 60 from $\mathrm{OVX}+\mathrm{E}$ animals). The confocal stacks were deconvolved with AutoDeblur (version 8.0.2.; Autoquant, Troy, NY) and imported to NeuroLucida for spine density analysis (see Fig. $1 c, d$ ), and to Volume Integration and Alignment System (VIAS; version 2.1) (Rodriguez et al., 2003) for 3D spine morphology analysis (see Fig. 1e). VIAS uses a maximal intensity method to create two-dimensional (2D) projections from the 3D stacks of CLSM images, and comprehensively scans every image for relative pixel intensity to develop an accurate $2 \mathrm{D}$ projection of the shaft, spine heads, and spine necks suitable for measurement. All spine measurements were done manually from $z$-axis projections obtained from the 3D z-stacks (total of 9393 spines for apical and 1297 spines for basal dendrites, 4495 spines for OVX+Veh, and 4898 spines for OVX+E). Rigorous criteria were established to ensure that measurements were unbiased and consistent. For example, neck length $\left(N_{l}\right)$ was always taken as the distance from the shaft to the most proximal edge of the spine head. Head length $\left(H_{l}\right)$ was taken from the pixel designated at the end of the neck, along the axis through the spine head in general register with the direction of the neck but bisecting the head symmetrically to allow for spine heads at an angle from the neck. Head diameter $\left(H_{d}\right)$ similarly bisected the spine head at a right angle to the measurement of head length (see Fig. 1e). No clear cutoffs that suggested qualitative categories were found with any combinations of the indices mentioned above. In addition, to determine whether changes in spine dimensions occurred equally across the entire spectrum of size measurements or are more pronounced in specific subpopulations of spines (e.g., the smallest and largest), all spine parameters from both groups were pooled and the 25th and the 75th percentiles for each parameter were determined. Then, for a given size parameter, the difference in proportions of spines below the 25 th percentile, as well as above the 75th percentile, was examined between groups (OVX+E vs OVX + Veh).

Statistical analysis. Statistical analyses were performed using ANOVA to assess possible differences in the various morphometric parameters between groups. The values are shown as means \pm SEM, calculated based on one aggregate (e.g., average) per animal. The two-way mixed model for repeated measures was used to test the treatment effect on dendritic length and branch number across apical and basal dendritic trees, and on spine density across basal and apical trees, both overall and for each individual apical branch order. For spine morphology measurements, the $\chi^{2}$ test was used to compare the proportions below the first quartile cutoffs between the groups, as well as the proportions above the third quartile cutoffs; in addition, the overall distribution difference between groups was examined using the Kolmogorov-Smirnov test. The Wilcoxon rank sums test was used to examine the group difference among small spines $\left(H_{d}<0.4 \mu \mathrm{m}\right)$. The statistical significance level was set at $\alpha=0.05$.

\section{Results}

\section{Measurements of dendritic arbors}

All intracellularly filled neurons that satisfied criteria for inclusion were fully reconstructed (a total of 168 neurons) and used for analyses of dendritic arbor, spine density, and spine morphology (Fig. 1). The average total dendritic lengths of apical and basal dendrites in the OVX $+\mathrm{E}$ group were $1568.7 \pm 87.2 \mu \mathrm{m}$ and $1734.1 \pm 124.6 \mu \mathrm{m}$, respectively (Table 1, Fig. $2 a$ ). There were no differences between these values and those from the OVX $+\mathrm{Veh}$ 
group (1603.4 $\pm 99.9 \mu \mathrm{m}$ for apical dendrites and $1875.0 \pm 99.2 \mu \mathrm{m}$ for basal dendrites; $p>0.3 ; n=7)$. Total branch numbers in both apical and basal dendrites in these neurons also did not differ across groups $(p>0.3 ; n=7)$ (Table 1 , Fig. $2 b$ ). The branching pattern of apical and basal dendrites was assessed using Sholl analysis with radial unit distances of $30 \mu \mathrm{m}$ (Fig. $2 c-f$ ). No statistically significant differences were observed between the two groups at any distance from the soma in both apical and basal dendrites, suggesting that overall dendritic complexity was also unaffected by $17 \beta$-estradiol.

\section{$17 \beta$-Estradiol effects on spine density and spine morphology}

Next, we investigated the possibility that, against this background of stability in gross dendritic architecture, $17 \beta$ estradiol might regulate spine number and morphology in the primate PFC. Quantitative 3D analyses revealed that long-term cyclic $17 \beta$-estradiol treatment substantially increased spine density across all dendritic branch orders of layer III pyramidal neurons in area 46 (Table 1, Fig. 3), resulting in a 31.5 and $24.1 \%$ increase among apical and basal dendrites, respectively, relative to values for aged OVX + Veh monkeys ( $p<0.01 ; n=7$, in both cases).

Spine morphology, including head size and related synapse size, bears an important relationship to glutamate receptor properties (Takumi et al., 1999; Matsuzaki et al., 2001; Kasai et al., 2003; Nimchinsky et al., 2004), receptor trafficking (Racz et al., 2004), and the capacity for synaptic plasticity (Kasai et al., 2003). Accordingly, we investigated the effects of $17 \beta$-estradiol on several indices of spine size (10,693 spines were analyzed). To determine whether there was an overall shift in the spine size distribution, or a disproportionate increase in the incidence of spines with small or large heads, we analyzed the frequency of spines in the top and bottom quartile for the subject population as a whole (i.e., OVX $+\mathrm{E}$ and OVX + Veh groups combined). The quartile analysis was done for $H_{d}, H_{l}$, and $N_{l}$. For spine head parameters $\left(H_{d}, H_{l}\right)$ examined, the proportion of observations from hormone-treated monkeys was greater in the lowest quartile, and lower in the highest quartile, relative to the vehicle-treated group $(p<0.001)$ (Table 2, Fig. 4). Also, nonparametric tests showed that the overall curves in the OVX + E group for $H_{d}$ and $H_{l}$ shifted leftward ( $p<0.001$ ) (Fig. 4). For spine neck parameter $N_{l}$, however, the quartile analysis indicated a higher proportion of $\mathrm{OVX}+\mathrm{E}$ spines in the highest quartile and a lower proportion in the lowest quartile $(p<0.001)$ (Table 2, Fig. 4). The overall curve of $N_{l}$ for OVX + E shifted to the right $(p<0.001$ ) (Fig. 4 ), suggesting that $\mathrm{E}$ treatment resulted in an overall increase in neck length. The effect of estrogen on the $H_{d}$ is particularly pronounced, suggesting that spines induced by $17 \beta$-estradiol treatment are predominantly those with a relatively small spine head, a morphological distinction linked to enhanced plasticity over larger spines (Kasai et al., 2003). To resolve further the size of the spine population preferentially affected by $17 \beta$-estradiol, we divided the range of $H_{d}$ into six bins and applied those bins to each animal, calculating each animal's cumulative percentage for each bin (Fig. 4). The six bins are the following with respect to $H_{d}$ : $<0.4 \mu \mathrm{m}, 0.4-0.5 \mu \mathrm{m}, 0.5-0.6 \mu \mathrm{m}, 0.6-0.7 \mu \mathrm{m}, 0.7-0.8 \mu \mathrm{m}$, a
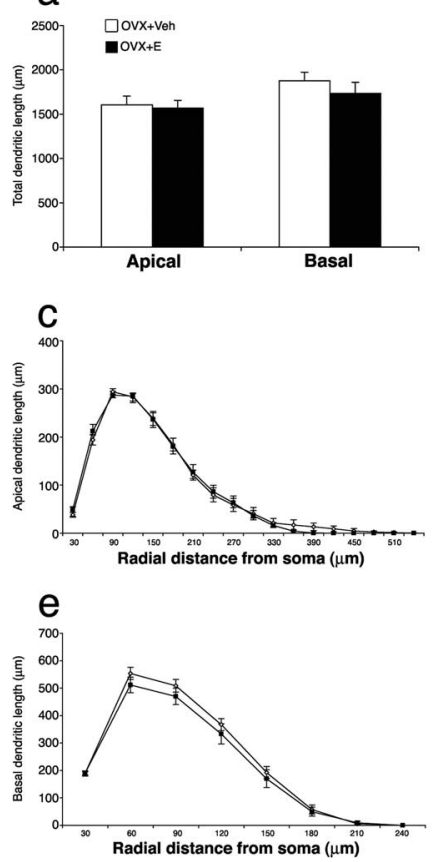

b
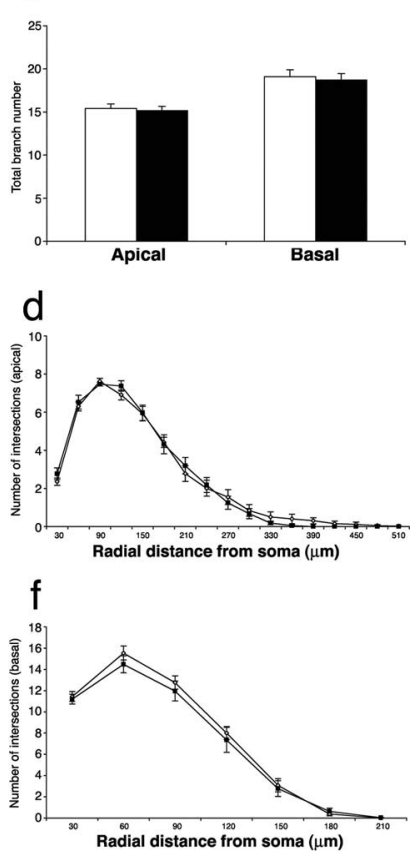

Figure 2. Quantitative analysis of $17 \beta$-estradiol effects on the global morphology of layer III neurons in area 46 . There were no $17 \beta$-estradiol-induced changes in total dendritic length $(\boldsymbol{a})$ and total branch number $(\boldsymbol{b})$ observed. Sholl analysis showed that long-term cyclic $17 \beta$ estradiol treatment had no effects on the degree of branching of layer III neuron in area 46 $(\boldsymbol{c}-\boldsymbol{f})$. A two-way mixed model for repeated measures was used for testing the treatment effect, both overall and for each individual radial distance point from the soma. Error bars represent SEM.

$>0.8 \mu \mathrm{m}$. The overall treatment effect was assessed with the Kolmogorov-Smirnov test using the cumulative percentages (see Fig. $4 b$ ). Although Figure $4 b$ suggests a favorable trend for the $\mathrm{OVX}+\mathrm{E}$ group, the overall difference did not reach significance; however, there are nearly $50 \%$ more small spines (i.e., $H_{d}<0.4$ ) in the $\mathrm{OVX}+\mathrm{E}$ group than in the $\mathrm{OVX}+\mathrm{Veh}$ group, and the difference is statically significant $(p<0.05)$.

These results demonstrate that the same long-term cyclical estradiol treatment that reverses age-related cognitive impairment on a test of spatiotemporal memory that requires the dor- 

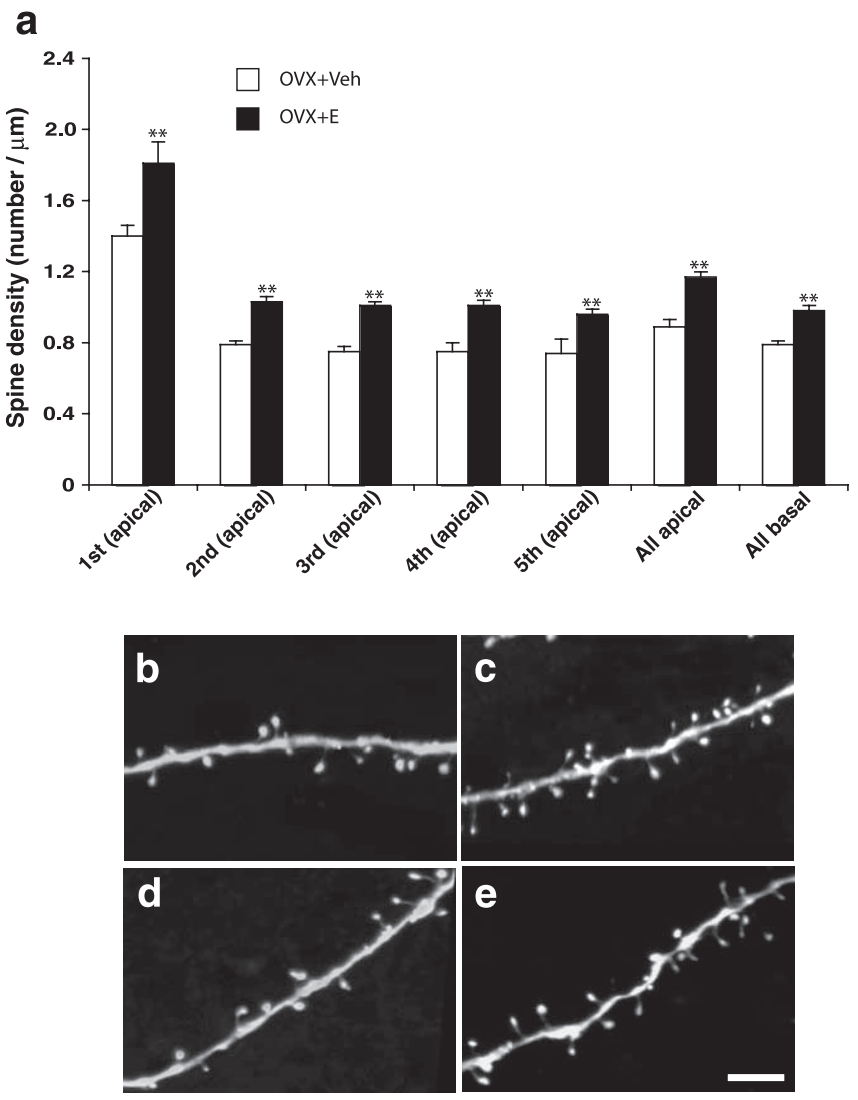

Figure 3. Histogram showing the quantitative data on spine density (spine number per micrometer of dendritic length). $17 \beta$-Estradiol significantly increased the apical and basal dendritic spine density across all dendritic orders $(\boldsymbol{a}) .{ }^{* *} p<0.01$; a two-way mixed model for repeated measures was used for testing the treatment effect, both overall and for each individual apical branch order. Error bars represent SEM. $\boldsymbol{b}, \boldsymbol{c}$, Examples of apical dendrites from $O V X+V$ eh and $O V X+E$ groups, respectively. $\boldsymbol{d}, \boldsymbol{e}$, Examples of basal dendrites from $0 V X+V$ eh and OVX +E groups, respectively. Note the higher density of the spines. Scale bar: (in $\boldsymbol{e}$ ) $\boldsymbol{b}-\boldsymbol{e}, 5$ $\mu \mathrm{m}$.

solateral PFC also increases PFC spine density, favoring the representation of small spines. By comparison, the small number of subjects available was not sufficient to permit a robust correlation analysis with the previously published behavioral data (Rapp et al., 2003), and scores averaged across the delay component of the DR task failed to predict individual variability on PFC spine density or morphology when control and hormone-treated animals were considered independently.

\section{Discussion}

Several studies have shown that $17 \beta$-estradiol induces spine formation in CA1 of hippocampus in young female rats (Woolley and McEwen, 1992, 1994), as well as in nonhuman primates (Le-

Table 2. Morphometric spine morphology measurement

\begin{tabular}{|c|c|c|c|c|c|c|c|}
\hline \multirow[b]{2}{*}{ Dimensions } & \multirow[b]{2}{*}{ Min-max values } & \multicolumn{2}{|c|}{ Percentile } & \multicolumn{2}{|c|}{$<25$ th $(\%)$} & \multicolumn{2}{|c|}{$>75$ th $(\%)$} \\
\hline & & 25th & 75th & OVX + Veh & $O V X+E$ & OVX + Veh & $O V X+E$ \\
\hline$H_{d}(\mu \mathrm{m})$ & $0.10-1.70$ & 0.41 & 0.64 & 21.6 & $29.3^{* * *}$ & 30.8 & $24.4^{* * *}$ \\
\hline$H_{l}(\mu \mathrm{m})$ & $0.14-2.01$ & 0.54 & 0.89 & 21.1 & $26.0 * * *$ & 28.3 & $23.7^{* * *}$ \\
\hline$N_{l}(\mu \mathrm{m})$ & $0.10-3.03$ & 0.32 & 0.86 & 27.9 & $24.8^{* * *}$ & 22.0 & $26.1^{* * *}$ \\
\hline
\end{tabular}

The minimum and maximum values (Min-max values) for the entire spine population (the first column) are shown. The targeted analyses of the 25th and 75 th percentiles were performed to determine whether changes in spine dimensions occur equally across the entire spectrum of size measurements or are more pronounced in specific subpopulations of spines (i.e., if spines from one treatment group are disproportionately represented in the smallest or largest $25 \%$ ) (see Materials and Methods). The data show that for $H_{d}$ and $H_{l}$ spines from $\mathrm{OVX}+\mathrm{E}$ animals are over-represented in the 1st quartile, and those from OVX + Veh animals are over-represented in the 4 th quartile; for $N_{l}$, however, spines from $\mathrm{VVX}+$ E animals are over-represented in the 4 th quartile and those from $0 \mathrm{VX}+$ Veh animals are over-represented in the 1 st quartile. ${ }^{* * *} p<0.001 ; \chi^{2}$ test. a

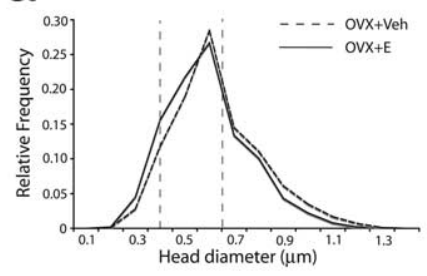

b
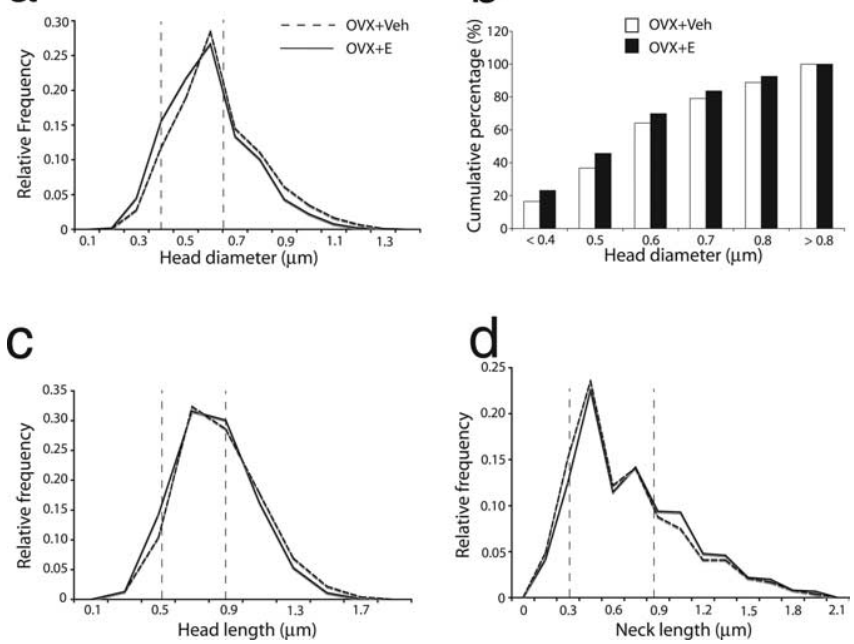

Figure 4. Frequency distributions of spine head dimensions. The dashed vertical lines show the 25 th and the 75 th percentiles of the entire spine population. The relative frequency curve ( $\boldsymbol{a}$, $\left.H_{d} ; \boldsymbol{c}, H_{l} ; \boldsymbol{d}, N_{l}\right)$ representing the OVX + E group showed a leftward shift for $H_{d}$ and $H_{l}$, which indicated that there were significantly more spines with smaller head dimensions and fewer spines with large head dimensions in the $0 \mathrm{VX}+\mathrm{E}$ group as compared with the $\mathrm{OVX}+\mathrm{Veh}$ group. The analysis also demonstrated a shift toward longer spine necks in the $\mathrm{OVX}+\mathrm{E}$ group (d). The analysis of $17 \beta$-estradiol effects on cumulative frequency across subgroups was based on $H_{d}$ measures $(\boldsymbol{b})$. The Kolmogorov-Smirnov test on $H_{d}$ cumulative percentages showed an overall trend toward smaller spines with estrogen treatment, but it failed to reach statistical significance. However a nonparametric Wilcoxon rank sums test showed that there are significantly more of the smallest spines $\left(H_{d}<0.4 \mu \mathrm{m}\right)$ in the OVX + Egroup than in the OVX + Veh group $(p<0.05)$

ranth et al., 2002; Hao et al., 2003), although the impact of $17 \beta$ estradiol on the neocortex, particularly in nonhuman primates, has been studied in far less detail. We have shown an increase in spines in layer I of area 46 in young macaque monkeys (Tang et al., 2004a) with brief cyclical $17 \beta$-estradiol therapy, and $17 \beta$ estradiol-induced alterations in monoaminergic and cholinergic innervation patterns have been demonstrated in the PFCs of young macaque monkeys (Kritzer and Kohama, 1999; Tinkler et al., 2004), which could also contribute to enhanced cognitive performance, although no such data are available on aged nonhuman primates. Human behavioral data have suggested that the PFC may be a key target for estrogens, perhaps even more so than the hippocampus (Keenan et al., 2001). Our behavioral data on the same aged rhesus monkeys used in this study support this view, in that cyclical $17 \beta$-estradiol treatment restored performance on a task dependent on the PFC to young normative values, whereas a task linked to the medial temporal lobe memory system showed a more modest improvement (P. R. Rapp et al., 2003). Here, we report the first data on spine and dendritic morphology that address potential synaptic underpinnings of $17 \beta$-estradiol-induced enhancement of PFC function in aged female monkeys. In addition, it is the first analysis using long-term (2-3 years) cyclical exposure to $17 \beta$-estradiol, the dominant estrogen to which female monkeys and women are exposed in a cyclical manner before menopause. The present data demonstrate clearly that the $17 \beta$ estradiol-induced enhancement of DR performance reported previously in these animals (P. R. Rapp et al., 2003) is accom- 
panied by an increase in spines per unit dendrite across the entire apical and basal dendritic trees of layer III pyramidal neurons, with no alteration in dendritic length, or branch number. This increase in spines is most pronounced among the small, thin spines that are viewed as the most motile, plastic, and least stable morphological type (Kasai et al., 2003). Virtually all layer III pyramidal neurons in area 46 participate in corticocortical circuitry and these neurons are vulnerable to aging (Hof and Morrison, 2004). Cholinergic and monoaminergic projections to monkey prefrontal cortex are also vulnerable to aging (Wenk et al., 1989; Arnsten, 1999) and responsive to estrogen, particularly in the supragranular layers (Kritzer and Kohama, 1998, 1999; Kompoliti et al., 2004; Tinkler et al., 2004), the layers that contain most of the dendritic arbor of our target neurons. Thus, estrogen treatment in aged monkeys potentially impacts key corticocortically projecting neurons, as well as the cholinergic and monoaminergic circuits that modulate these circuits. These data have important implications for $17 \beta$-estradiol-induced plasticity in the PFC in the context of aging and the potential for reversing agerelated cognitive decline.

\section{Functional implications of spine number and spine morphology}

Hippocampal spine number has been linked to learning and memory (Moser et al., 1994; Trommald et al., 1996). The increase in density of spines on layer III pyramidal neurons in area 46 reported here is consistent with our previous analyses of young animals using a stereologic approach to count spinophilinimmunoreactive spines (Tang et al., 2004a). In that study, the analysis was confined to layer I because of methodological limitations, but importantly, $17 \beta$-estradiol led to a very dramatic increase in spine number in layer I of area 46 , yet had no such effect in the primary visual cortex of the same animals, suggesting that area 46 is particularly responsive to $17 \beta$-estradiol with respect to spine number (Tang et al., 2004a), although we cannot rule out an estradiol effect on related prefrontal regions. This regional selectivity is reminiscent of the rodent studies demonstrating high spine turnover in the somatosensory cortex (Trachtenberg et al., 2002), but more stability in spine morphology and number in the visual cortex (Holtmaat et al., 2005). Although electron microscopic studies will be required to prove that the observed increase in spines is accompanied by increased axospinous synapse density, at least in both rat (Gould et al., 1990; Woolley and McEwen, 1992) and monkey hippocampus (Hao et al., 2003; Tang et al., 2004b), the estrogen effect on spines is manifested as an increase in axospinous synapses as well.

Our data on spine morphology demonstrating a shift in spine size such that small spines became more prevalent allows us to consider the increase in spine number in the context of spine stability and plasticity. Smaller spines have been shown to be less stable and more motile (Trachtenberg et al., 2002; Kasai et al., 2003; Holtmaat et al., 2005), and as a result, more plastic than large spines (Grutzendler et al., 2002). Spine size is also positively correlated with synapse size (Harris and Stevens, 1989), and larger postsynaptic densities have more AMPA receptors (Nusser et al., 1998; Kharazia and Weinberg, 1999; Takumi et al., 1999), consistent with the relative stability credited to the large spines (Kasai et al., 2003). Small spines are more dominated by NMDA receptors (Kasai et al., 2003), and are more sensitive to $\mathrm{Ca}^{2+}$ mediated signaling than large spines (Nimchinsky et al., 2004). Spine size is also related to the distribution of endocytic proteins, with such proteins closer to the synaptic edge in small spines (Racz et al., 2004), which might facilitate insertion into the syn- apse. The specific impact on receptor dynamics of a small magnitude shift in size such as we observed (i.e., a mean decrease in spine volume of $\sim 25 \%$; data not shown) is hard to predict, although it is consistent with an increase in spines that are perhaps more dynamic with respect to receptor trafficking and $\mathrm{Ca}^{2+}$ mediated processes. In the context of plasticity, Kasai et al. (2003) have proposed that the small spines represent "learning spines" that can either retract or become stabilized in the context of learning. By this view large spines are "memory spines" that are stabilized and retain information over the long term. It would appear that our analysis captured a time-point (i.e., $24 \mathrm{~h}$ after treatment) where there was a particularly high representation of small spines, a subset of which might be poised for an increase in size and stability and consolidation in the context of learning (Matsuzaki et al., 2004). Although we currently have no equivalent data on young monkeys, it is particularly important that these effects occurred in aged monkeys, because pyramidal neurons in the PFC have been shown to be altered physiologically in aged monkeys (Chang et al., 2004) and structurally in humans (Jacobs et al., 1997). Such dynamic shifts in spine morphology and number is in keeping with the conceptualization that PFC functions not only to learn the "rules of the game," but also to allow updating of those rules in a dynamic continuous manner (Goldman-Rakic, 1996; Miller, 2000). In this context, the cyclic delivery of estradiol may be critical. Animals were exposed to an injection every $21 \mathrm{~d}$ for two to three years over the course of their behavioral assessment, and were killed $24 \mathrm{~h}$ after the last injection. We assume that the increase in spines is partially or primarily an acute effect. Although analyses of spines and synapses at additional time points further removed from the cyclical treatment would be informative in this regard, no such data currently exist. Notably, DR performance was stable across the $21 \mathrm{~d}$, with no detectable decline in accuracy in the days before the next injection, when circulating $17 \beta$-estradiol levels were low. Under normal physiological conditions, exposure to $17 \beta$-estradiol is highly cyclical (Shideler et al., 1993). We suggest that cyclical exposure to $17 \beta$-estradiol or at least cyclical peaks may be most effective in inducing spine generation, turnover, and consolidation, thereby facilitating learning, and that dynamic regulation of spine number and morphology may be as important as absolute spine number. The therapy used in this case was hormonal, but the data have broader implications, demonstrating a capacity for plasticity that may be important for treating age-related cognitive decline through related signaling mechanisms.

\section{Clinical implications}

The WHI studies concluded that the overall health risks of commonly prescribed hormone therapy (i.e., PremPro) exceed benefits (Espeland et al., 2004), that this formulation does not improve cognitive function (S. R. Rapp et al., 2003; Shumaker et al., 2003), and in fact, "increases the risk for probable dementia in postmenopausal women aged 65 or older" (Shumaker et al., 2003). In the ensuing discussion, the distinction between daily administration of PremPro (0.625 mg CEEs/2.5 mg MPA), and other potential regimens was rarely mentioned. For example, MPA, a chemically modified progestin that differs from ovarian progesterone in its bioactivity (Nilsen and Brinton, 2002), antagonizes some neuronal effects of $17 \beta$-estradiol (Nilsen and Brinton, 2002). A later study from the WHI concluded that CEEs alone carried less risk but did not improve cognitive function (Anderson et al., 2004; Shumaker et al., 2004). However, 17 $\beta$ estradiol, the most potent naturally occurring estrogen, is a minor component of CEEs, suggesting that pure $17 \beta$-estradiol as 
used in our studies of nonhuman primates may be a more suitable formulation. Treatment in the WHI trial was initiated in women $\geq 65$ years old, who may be beyond the time-frame for optimal neuronal response to estrogen therapy (Turgeon et al., 2004), whereas our treatment was initiated within months of ovariectomy. Also, our monkeys were premenopausal or perimenopausal, corresponding to treatment of women in their early to mid-fifties rather than mid-sixties. The importance of age at onset of treatment has been demonstrated at multiple levels in rodent studies (Gibbs, 2000; Adams et al., 2001a,b; Savonenko and Markowska, 2003). Moreover, standard practice in women is to give the CEEs, with or without MPA, continuously, which is quite different from normal hormone fluctuations (Turgeon et al., 2004). Sherwin and McGill recently reviewed the effects of estrogens on cognition in women, concluding that there is extensive evidence of estrogen-induced enhancement, but that combined therapies with a progestin may complicate and modulate the cognitive response to such effects (Sherwin and McGill, 2003). The question of whether hormone treatment is protective against $\mathrm{AD}$ has also been controversial (Henderson et al., 2000; Mulnard et al., 2000; Asthana et al., 2001), with the recently published Cache County study (Zandi et al., 2002) demonstrating substantial protection only when unopposed estrogen administration is started early, within 10 years of the onset of menopause. From this perspective, continued translational efforts using animal models of hormone replacement will be required to clarify the importance of formulation, schedule, and time of initiation of hormone treatment and the relative efficiency of these manipulations for improving the cognitive and neurobiological outcome of aging in primates.

\section{References}

Adams MM, Shah RA, Janssen WG, Morrison JH (2001a) Different modes of hippocampal plasticity in response to estrogen in young and aged female rats. Proc Natl Acad Sci USA 98:8071-8076.

Adams MM, Oung T, Morrison JH, Gore AC (2001b) Length of postovariectomy interval and age, but not estrogen replacement, regulate $\mathrm{N}$-methyl-D-aspartate receptor mRNA levels in the hippocampus of female rats. Exp Neurol 170:345-356.

Anderson GL, Limacher M, Assaf AR, Bassford T, Beresford SA, Black H, Bonds D, Brunner R, Brzyski R, Caan B, Chlebowski R, Curb D, Gass M, Hays J, Heiss G, Hendrix S, Howard BV, Hsia J, Hubbell A, Jackson R, et al. (2004) Effects of conjugated equine estrogen in postmenopausal women with hysterectomy: the Women's Health Initiative randomized controlled trial. JAMA 291:1701-1712.

Arnsten AFT (1999) Age-related cognitive deficits and neurotransmitters: the role of catecholamine mechanisms in prefrontal cortical cognitive decline. In: Cerebral cortex, neurodegenerative and age-related changes in structure and function of cerebral cortex (Peters A, Morrison JH, eds), pp 89-110. New York: Kluwer Academic/Plenum.

Asthana S, Baker LD, Craft S, Stanczyk FZ, Veith RC, Raskind MA, Plymate SR (2001) High-dose estradiol improves cognition for women with AD: results of a randomized study. Neurology 57:605-612.

Chang YM, Rosene DL, Killiany RJ, Mangiamele LA, Luebke JI (2004) Increased action potential firing rates of layer $2 / 3$ pyramidal cells in the prefrontal cortex are significantly related to cognitive performance in aged monkeys. Cereb Cortex 15:409-418.

Duan H, Wearne SL, Rocher AB, Macedo A, Morrison JH, Hof PR (2003) Age-related dendritic and spine changes in corticocortically projecting neurons in macaque monkeys. Cereb Cortex 13:950-961.

Espeland MA, Rapp SR, Shumaker SA, Brunner R, Manson JE, Sherwin BB, Hsia J, Margolis KL, Hogan PE, Wallace R, Dailey M, Freeman R, Hays J (2004) Conjugated equine estrogens and global cognitive function in postmenopausal women: Women's Health Initiative memory study. JAMA 291:2959-2968.

Gazzaley AH, Weiland NG, McEwen BS, Morrison JH (1996) Differential regulation of NMDAR1 mRNA and protein by estradiol in the rat hippocampus. J Neurosci 16:6830-6838.
Gibbs RB (2000) Long-term treatment with estrogen and progesterone enhances acquisition of a spatial memory task by ovariectomized aged rats. Neurobiol Aging 21:107-116.

Gibbs RB (2002) Basal forebrain cholinergic neurons are necessary for estrogen to enhance acquisition of a delayed matching-to-position T-maze task. Horm Behav 42:245-257.

Gilardi KV, Shideler SE, Valverde CR, Roberts JA, Lasley BL (1997) Characterization of the onset of menopause in the rhesus macaque. Biol Reprod 57:335-340.

Goldman-Rakic PS (1996) The prefrontal landscape: implications of functional architecture for understanding human mentation and the central executive. Philos Trans R Soc Lond B Biol Sci 351:1445-1453.

Goldman-Rakic PS (2002) The "psychic cell” of Ramón y Cajal. Prog Brain Res 136:427-434

Gould E, Woolley CS, Frankfurt M, McEwen BS (1990) Gonadal steroids regulate dendritic spine density in hippocampal pyramidal cells in adulthood. J Neurosci 10:1286-1291.

Grutzendler J, Kasthuri N, Gan WB (2002) Long-term dendritic spine stability in the adult cortex. Nature 420:812-816.

Hao J, Janssen WG, Tang Y, Roberts JA, McKay H, Lasley B, Allen PB, Greengard P, Rapp PR, Kordower JH, Hof PR, Morrison JH (2003) Estrogen increases the number of spinophilin-immunoreactive spines in the hippocampus of young and aged female rhesus monkeys. J Comp Neurol 465:540-550.

Harris KM, Stevens JK (1989) Dendritic spines of CA 1 pyramidal cells in the rat hippocampus: serial electron microscopy with reference to their biophysical characteristics. J Neurosci 9:2982-2997.

Henderson VW, Paganini-Hill A, Miller BL, Elble RJ, Reyes PF, Shoupe D, McCleary CA, Klein RA, Hake AM, Farlow MR (2000) Estrogen for Alzheimer's disease in women: randomized, double-blind, placebocontrolled trial. Neurology 54:295-301.

Hof PR, Morrison JH (2004) The aging brain: morphomolecular senescence of cortical circuits. Trends Neurosci 27:607-613.

Holtmaat AJ, Trachtenberg JT, Wilbrecht L, Shepherd GM, Zhang X, Knott GW, Svoboda K (2005) Transient and persistent dendritic spines in the neocortex in vivo. Neuron 45:279-291.

Jacobs B, Driscoll L, Schall M (1997) Life-span dendritic and spine changes in areas 10 and 18 of human cortex: a quantitative Golgi study. J Comp Neurol 386:661-680.

Kasai H, Matsuzaki M, Noguchi J, Yasumatsu N, Nakahara H (2003) Structure-stability-function relationships of dendritic spines. Trends Neurosci 26:360-368.

Keenan PA, Ezzat WH, Ginsburg K, Moore GJ (2001) Prefrontal cortex as the site of estrogen's effect on cognition. Psychoneuroendocrinology 26:577-590.

Kharazia VN, Weinberg RJ (1999) Immunogold localization of AMPA and NMDA receptors in somatic sensory cortex of albino rat. J Comp Neurol 412:292-302.

Kompoliti K, Chu Y, Polish A, Roberts J, McKay H, Mufson EJ, Leurgans S, Morrison JH, Kordower JH (2004) Effects of estrogen replacement therapy on cholinergic basal forebrain neurons and cortical cholinergic innervation in young and aged ovariectomized rhesus monkeys. J Comp Neurol 472:193-207.

Kritzer MF, Kohama SG (1998) Ovarian hormones influence the morphology, distribution, and density of tyrosine hydroxylase immunoreactive axons in the dorsolateral prefrontal cortex of adult rhesus monkeys. J Comp Neurol 395:1-17.

Kritzer MF, Kohama SG (1999) Ovarian hormones differentially influence immunoreactivity for dopamine $\beta$-hydroxylase, choline acetyltransferase, and serotonin in the dorsolateral prefrontal cortex of adult rhesus monkeys. J Comp Neurol 409:438-451.

Leranth C, Shanabrough M, Redmond Jr DE (2002) Gonadal hormones are responsible for maintaining the integrity of spine synapses in the CAl hippocampal subfield of female nonhuman primates. J Comp Neurol 447:34-42.

Matsuzaki M, Ellis-Davies GC, Nemoto T, Miyashita Y, Iino M, Kasai H (2001) Dendritic spine geometry is critical for AMPA receptor expression in hippocampal CAl pyramidal neurons. Nat Neurosci 4:1086-1092.

Matsuzaki M, Honkura N, Ellis-Davies GC, Kasai H (2004) Structural basis of long-term potentiation in single dendritic spines. Nature 429:761-766. 
McEwen BS (2001) Invited review: estrogens effects on the brain: multiple sites and molecular mechanisms. J Appl Physiol 91:2785-2801.

Miller EK (2000) The prefrontal cortex and cognitive control. Nat Rev Neurosci 1:59-65.

Moser MB, Trommald M, Andersen P (1994) An increase in dendritic spine density on hippocampal CA1 pyramidal cells following spatial learning in adult rats suggests the formation of new synapses. Proc Natl Acad Sci USA 91:12673-12675.

Mulnard RA, Cotman CW, Kawas C, van Dyck CH, Sano M, Doody R, Koss E, Pfeiffer E, Jin S, Gamst A, Grundman M, Thomas R, Thal LJ (2000) Estrogen replacement therapy for treatment of mild to moderate Alzheimer disease: a randomized controlled trial. Alzheimer's disease cooperative study. JAMA 283:1007-1015.

Nilsen J, Brinton RD (2002) Impact of progestins on estrogen-induced neuroprotection: synergy by progesterone and 19-norprogesterone and antagonism by medroxyprogesterone acetate. Endocrinology 143:205-212.

Nimchinsky EA, Yasuda R, Oertner TG, Svoboda K (2004) The number of glutamate receptors opened by synaptic stimulation in single hippocampal spines. J Neurosci 24:2054-2064.

Nusser Z, Lujan R, Laube G, Roberts JD, Molnar E, Somogyi P (1998) Cell type and pathway dependence of synaptic AMPA receptor number and variability in the hippocampus. Neuron 21:545-559.

Racz B, Blanpied TA, Ehlers MD, Weinberg RJ (2004) Lateral organization of endocytic machinery in dendritic spines. Nat Neurosci 7:917-918.

Rapp PR, Morrison JH, Roberts JA (2003) Cyclic estrogen replacement improves cognitive function in aged ovariectomized rhesus monkeys. J Neurosci 23:5708-5714.

Rapp SR, Espeland MA, Shumaker SA, Henderson VW, Brunner RL, Manson JE, Gass ML, Stefanick ML, Lane DS, Hays J, Johnson KC, Coker LH, Dailey M, Bowen D (2003) Effect of estrogen plus progestin on global cognitive function in postmenopausal women: the Women's Health Initiative memory study: a randomized controlled trial. JAMA 289:2663-2672.

Rodriguez A, Ehlenberger D, Kelliher K, Einstein M, Henderson SC, Morrison JH, Hof PR, Wearne SL (2003) Automated reconstruction of threedimensional neuronal morphology from laser scanning microscopy images. Methods 30:94-105.

Rudick CN, Woolley CS (2001) Estrogen regulates functional inhibition of hippocampal CA1 pyramidal cells in the adult female rat. J Neurosci 21:6532-6543.

Rudick CN, Gibbs RB, Woolley CS (2003) A role for the basal forebrain cholinergic system in estrogen-induced disinhibition of hippocampal pyramidal cells. J Neurosci 23:4479-4490.

Savonenko AV, Markowska AL (2003) The cognitive effects of ovariectomy and estrogen replacement are modulated by aging. Neuroscience 119:821-830

Sherwin BB, McGill J (2003) Oestrogen plus progestin doubles the risk of dementia in post-menopausal women. Evid Based Ment Health 6:111.

Shideler SE, Ortuno AM, Moran FM, Moorman EA, Lasley BL (1993) Simple extraction and enzyme immunoassays for estrogen and progesterone metabolites in the feces of Macaca fascicularis during non-conceptive and conceptive ovarian cycles. Biol Reprod 48:1290-1298.

Shideler SE, Gee NA, Chen J, Laughlin LS, Rapp PR, Morrison JH, Roberts JA, Moran FM, Lasley BL (2003) Contribution of ovarian steroid production to urinary estrone conjugate concentrations in Macaca mulatta. Am J Primatol 61:111-121.
Shumaker SA, Legault C, Rapp SR, Thal L, Wallace RB, Ockene JK, Hendrix SL, Jones III BN, Assaf AR, Jackson RD, Kotchen JM, Wassertheil-Smoller S, Wactawski-Wende J (2003) Estrogen plus progestin and the incidence of dementia and mild cognitive impairment in postmenopausal women: the Women's Health Initiative memory study: a randomized controlled trial. JAMA 289:2651-2662.

Shumaker SA, Legault C, Kuller L, Rapp SR, Thal L, Lane DS, Fillit H, Stefanick ML, Hendrix SL, Lewis CE, Masaki K, Coker LH (2004) Conjugated equine estrogens and incidence of probable dementia and mild cognitive impairment in postmenopausal women: Women's Health Initiative memory study. JAMA 291:2947-2958.

Simpkins JW, Singh M (2004) Consortium for the assessment of research on progestins and estrogens (CARPE) Fort Worth, Texas August 1-3, 2003. J Womens Health (Larchmt) 13:1165-1168.

Takumi Y, Ramirez-Leon V, Laake P, Rinvik E, Ottersen OP (1999) Different modes of expression of AMPA and NMDA receptors in hippocampal synapses. Nat Neurosci 2:618-624.

Tang Y, Janssen WG, Hao J, Roberts JA, McKay H, Lasley B, Allen PB, Greengard P, Rapp PR, Kordower JH, Hof PR, Morrison JH (2004a) Estrogen replacement increases spinophilin-immunoreactive spine number in the prefrontal cortex of female rhesus monkeys. Cereb Cortex 14:215-223.

Tang Y, Minwalla L, Janssen WGM, Adams MM, McKay H, Roberts JA, Hof PR, Rapp PR, Morrison JH (2004b) Effects of estrogen on excitatory synapses in hippocampal CA1 of aged female rhesus monkeys. Soc Neurosci Abstr 30:757.16.

Tinkler GP, Tobin JR, Voytko ML (2004) Effects of two years of estrogen loss or replacement on nucleus basalis cholinergic neurons and cholinergic fibers to the dorsolateral prefrontal and inferior parietal cortex of monkeys. J Comp Neurol 469:507-521.

Trachtenberg JT, Chen BE, Knott GW, Feng G, Sanes JR, Welker E, Svoboda $\mathrm{K}$ (2002) Long-term in vivo imaging of experience-dependent synaptic plasticity in adult cortex. Nature 420:788-794.

Trommald M, Hulleberg G, Andersen P (1996) Long-term potentiation is associated with new excitatory spine synapses on rat dentate granule cells. Learn Mem 3:218-228.

Turgeon JL, McDonnell DP, Martin KA, Wise PM (2004) Hormone therapy: physiological complexity belies therapeutic simplicity. Science 304:1269-1273.

Wenk GL, Pierce DJ, Struble RG, Price DL, Cork LC (1989) Age-related changes in multiple neurotransmitter systems in the monkey brain. Neurobiol Aging 10:11-19.

Woolley CS, McEwen BS (1992) Estradiol mediates fluctuation in hippocampal synapse density during the estrous cycle in the adult rat. J Neurosci 12:2549-2554.

Woolley CS, McEwen BS (1994) Estradiol regulates hippocampal dendritic spine density via an $N$-methyl-D-aspartate receptor-dependent mechanism. J Neurosci 14:7680-7687.

Woolley CS, Weiland NG, McEwen BS, Schwartzkroin PA (1997) Estradiol increases the sensitivity of hippocampal CA1 pyramidal cells to NMDA receptor-mediated synaptic input: correlation with dendritic spine density. J Neurosci 17:1848-1859.

Zandi PP, Carlson MC, Plassman BL, Welsh-Bohmer KA, Mayer LS, Steffens DC, Breitner JC (2002) Hormone replacement therapy and incidence of Alzheimer disease in older women: the Cache County study. JAMA 288: 2123-2129. 